3 Farrow, S. C., Fisher, D. J., and Johnson, D. B., British Medical fournal, 1972, 3, 686.

4 British Medical fournal, 1974, 3, 703.

5 Nelson, S. D., and Tovey, G. H., British Medical fournal, 1974, 1, 622

6 Martin, D. C., Smith, G. A., and Fareed, D. O., Surgical Forum, 1969, 20, 529.

7 Belzer, F. O., Transplantation Proceedings, 1971, 3, 268.

${ }^{8}$ Frost, A. B., et al., Lancet, 1970, 1, 620.

9 Scott, D. F., et al., Transplantation, 1971, 11, 90.

10 Festenstein, H., et al., Lancet, 1971, 2, 225.

11 Ackermann, J. R., and Snell, M. E., British fournal of Urology, 1968, 40, 515.
12 Calne, R. Y., British Medical fournal, 1969, 2, 565

13 Gelin, L. E. et al., Scandinavian Fournal of Urology and Nephrology, 1968, 2,1 .

${ }^{14}$ Collins, G. M., Bravo-Shugarman, M. and Terasaki, P. I., Lancet, 1969 , 2, 1219.

15 Bell, P. F. R., et al., British Medical fournal, 1972, 4, 408.

16 Hall, C. L., et al., Lancet, 1974, 1, 532.

17 Belzer, F. O., Ashby, B. S., and Dunphy, J. E., Lancet, 1967, 2, 536.

18 Hartley, L. C. J., Collins, G. M., and Clunie, G. J. A., New England fournal of Medicine, 1971, 285, 1049.

19 Tanaka, N., Stevens, L. E., and Terasaki, P. I., Transplantation, 1971, $12,348$.

${ }^{20}$ Collaborative Study, Lancet, 1972, 2, 887.

\title{
Criteria of Fitness for Anaesthesia in Patients with Chronic Obstructive Lung Disease
}

\author{
J. S. MILLEDGE, J. F. NUNN
}

British Medical fournal, 1975, 3, 670-673

\begin{abstract}
Summary
Twelve patients with severe chronic obstructive lung disease undergoing 15 operations were assessed with preoperative lung function tests and blood gas estimations. Their operative and postoperative course was followed. There were no deaths or serious complications. Patients fell into three groups: those with low respiratory capacity but normal blood gases, who required no special respiratory treatment apart from physiotherapy and antibiotics; those with hypoxaemia but normal arterial carbon dioxide pressure, who needed more prolonged oxygen treatment after operation; and those with hypoxaemia and hypercapnia, who needed postoperative ventilatory support.
\end{abstract}

While forced expiratory volume in one second (FEV $)_{1}$ is a good screening test in preoperative assessment it should be supplemented by arterial blood gas estimations in patients with an $\mathrm{FEV}_{1}$ of less than 1 litre.

\section{Introduction}

Doctors are often confronted with the problem of whether to recommend or accept for surgery a patient with chronic obstructive lung disease. The decision rests partly on surgical considerations but also on the likely effect of anaesthesia and surgery on the respiratory state of the patient. This is difficult to predict, and numerous reviews have described techniques for preoperative assessment of respiratory function but given no guidance on interpretation of findings in relation to the expected course of events.

The commonest routine preoperative test of pulmonary function is the measurement of forced vital capacity, with the results expressed as the forced expiratory volume in one second $\left(\mathrm{FEV}_{1}\right)$ and also as a percentage of the slow vital capacity (VC). The theoretical hazards of impaired ventilatory capacity in relation to anaesthesia are widely appreciated, but there is no reference to the actual level of reduction of $\mathrm{FEV}_{1}$

Division of Anaesthesia, Clinical Research Centre, Northwick Park Hospital, Harrow, Middlesex HA1 3UJ

J. S. MILlEDGE, M.D., F.R.C.P., Consultant Physician and M.R.C Scientific Staff member

J. F. NUNN, M.D., F.F.A. R.C.S., Head of Division which in itself constitutes a definite hazard or contraindication to anaesthesia and surgery. Diament and Palmer, ' however, claim that a reduction in $\mathrm{FEV}_{1}$ below $70^{\circ}$ indicates that a patient is at risk of developing postoperative pulmonary complications, but this conclusion was not supported by any study of their patients' progress after operation.

Published works gives little or no guidance on the potential hazard in patients with an exceptionally low $\mathrm{FEV}_{1}$. The lowest value reported is 0.81 litre. $^{2}$ Thornton $^{3}$ lists several patients with values below 1 litre who underwent surgery but gives no details of progress during or after surgery. We therefore collected details of 15 anaesthetics in 12 patients with grossly reduced $\mathrm{FEV}_{1}$ (range $0.45-1.04$ litres) to determine whether a reduction of FEV, to these low levels in itself introduces a hazard to anaesthesia for routine surgery. In most cases we also noted the preoperative blood gas levels, since Stein et al. ${ }^{2}$ reported that a raised alveolar carbon dioxide pressure was an important factor discriminating those patients who would develop postoperative pulmonary complications.

\section{Patients and Management}

Fifteen operations were performed on 12 patients with chronic obstructive airway disease who presented consecutively for surgery with an FEV 1 of 1 litre or less. The anaesthetic management was entirely at the discretion of the seven different anaesthetists on whose lists the patients came for surgery.

Preoperative Assessment.-Patients were subjected to routine preoperative clinical assessment by the anaesthetist. Tests of ventilatory capacity were also carried out in all patients. $\mathrm{FEV}_{1}$ and VC were measured with a Vitalograph dry spirometer, usually one or two days before operation. Predicted normal values were taken from the data of Cotes. ${ }^{4}$ Arterial gases were measured preoperatively in 10 patients using a Corning Eel model 165, oxygen pressure $\left(\mathrm{PaO}_{2}\right)$ calibration being carried out with $30^{\circ}$ o glycerol in water equilibrated with air. The normal range of blood gases was taken from the data of Raine and Bishop. $^{5}$

Preoperative Management.-All patients received preoperative pulmonary physiotherapy except one patient (case 12) who was admitted as an emergency and four (cases 2, 7, 9, and 11) for whom it was deemed unnecessary. All patients received antibiotics before and after surgery. Details of premedication are given in table I.

Anaesthesia.-Induction of anaesthesia was with thiopentone in all cases. Spontaneous respiration and anaesthesia with halothane and nitrous oxide without endotracheal intubation was used four times for relatively minor operations not requiring relaxation. For the remaining 11 operations, patients were intubated and ventilated artificially with a Manley Ventilator incorporated in a Blease "Northwick Park" anaesthetic apparatus. Anaesthesia was maintained with nitrous oxide supplemented with lhalothane, fentanyl, or diamorphine. The relaxant pancuronium was used in nine cases. In six cases 
TABle I-Operations Performed and Anaesthetics Used in 12 Patients with Chronic Obstructive Lung Diseases

\begin{tabular}{|c|c|c|c|c|c|c|c|c|}
\hline $\begin{array}{l}\text { Case } \\
\text { No. }\end{array}$ & $\begin{array}{l}\text { Premedication } \\
(\mathrm{mg})\end{array}$ & Operation & $\begin{array}{l}\text { Induction } \\
(\mathrm{mg})\end{array}$ & Maintenance & Airway & Resp̄iration & $\begin{array}{l}\text { Length of } \\
\text { Operation } \\
\text { (min) }\end{array}$ & $\begin{array}{c}\text { Postoperative } \\
\text { Regional Analgesia }\end{array}$ \\
\hline 1 & $\begin{array}{l}\text { Morph. (2.5), } \\
\text { Atrop. (0.6), } \\
\text { Drop. (2.5), } \\
\text { Hydc. (100) }\end{array}$ & $\begin{array}{l}\text { Cystoscopy, } \\
\text { bilateral hernia }\end{array}$ & Thiop. (300) & $\mathrm{N}_{2} \mathrm{O} / \mathrm{Hal}$ & Mask & Spontaneous & 90 & Epidural \\
\hline $2 \mathrm{a}$ & $\begin{array}{l}\text { Papa. (10) } \\
\text { Hyos. (0.2), } \\
\text { Hydc. (100) }\end{array}$ & $\begin{array}{l}\text { Sigmoid } \\
\text { colectomy }\end{array}$ & Thiop. (100) & $\begin{array}{l}\mathrm{N}_{2} \mathrm{O} / \mathrm{Hal}, \\
\quad \text { Panc }(6 \mathrm{mg})\end{array}$ & E.T. tube & Artificial & 185 & \\
\hline $2 \mathrm{~b}$ & Papa. (10), & Closure & Thiop. (100) & $\mathrm{N}_{2} \mathrm{O} / \mathrm{Hal}$, & E.T. tube & Artificial & 45 & \\
\hline $3 \mathrm{a}$ & $\begin{array}{l}\text { Morph. (5), } \\
\text { Drop. (5), } \\
\text { Atrop (0.6) }\end{array}$ & Cystoscopy & Thiop. (150) & $\mathrm{N}_{2} \mathrm{O} / \mathrm{Hal}$ & Mask & Spontaneous & 25 & \\
\hline $3 b$ & $\begin{array}{l}\text { Papa. (10), } \\
\text { Hyosc. }(0 \cdot 2)\end{array}$ & Cystectomy & Thiop. (250) & $\begin{array}{l}\mathrm{N}_{2} \mathrm{O} / \mathrm{Hal}, \\
\text { Panc (8 mg) }\end{array}$ & E.T tube & Artificial & 180 & \\
\hline 4 & Hydc. (100) & $\begin{array}{l}\text { Transvesical } \\
\text { prostatectomy }\end{array}$ & Thiop. (50) & $\mathrm{N}_{2} \mathrm{O} / \mathrm{Hal}$ & E.T. tube & Artificial & 80 & Epidural \\
\hline 5 & $\begin{array}{l}\text { Papa. (15), } \\
\text { Hyosc. }(0.3)\end{array}$ & $\begin{array}{l}\text { Cryodiathermy } \\
\text { to eye }\end{array}$ & Thiop. (50) & $\begin{array}{l}\mathrm{N}_{2} \mathrm{O} \text {, fentanyl, } \\
\text { Panc (11 mg) }\end{array}$ & E.T. tube & Artificial & 180 & \\
\hline 6 & $\begin{array}{l}\text { Papa. (10), } \\
\text { Hyosc. }(0.2)\end{array}$ & $\begin{array}{l}\text { Transurethral } \\
\text { prostatectomy }\end{array}$ & Thiop. (250) & $\mathrm{N}_{2} \mathrm{O}$, Panc $(8 \mathrm{mg})$ & E.T. tube & Artificial & 45 & Epidural \\
\hline 7 & $\begin{array}{l}\text { Papa. (10), } \\
\text { Hyosc. }(0 \cdot 2)\end{array}$ & $\begin{array}{l}\text { Repair of } \\
\text { incisional hernia }\end{array}$ & Thiop. (100) & $\begin{array}{l}\mathrm{N}_{2} \mathrm{O} / \mathrm{Hal}, \\
\text { Panc (4 mg) }\end{array}$ & E.T. tube & Artificial & 150 & Epidural \\
\hline 8 & $\begin{array}{l}\text { Morph. (7.5), } \\
\text { Drop. (5), } \\
\text { Atrop. (0.6) }\end{array}$ & Cholecystectomy & Thiop. (250) & $\begin{array}{l}\mathrm{N}_{2} \mathrm{O} \text {, diamorph. } \\
\text { (4 mg), } \\
\text { Panc } 6 \mathrm{mg})\end{array}$ & E.T. tube & Artificial & 130 & $\begin{array}{l}\text { Intercostal block } \\
\text { ( } \mathrm{T} \text { 6-12, bupivicaine) }\end{array}$ \\
\hline 9 & Atrop. $(0 \cdot 6)$ & $\begin{array}{l}\text { Cystoscopy, } \\
\text { prostatectomy, } \\
\text { repair hernia }\end{array}$ & Thiop. (225) & $\begin{array}{c}\mathrm{N}_{2} \mathrm{O} / \mathrm{Hal}, \\
\text { fentanyl }\end{array}$ & E.T. tube & Artificial & 75 & Epidural \\
\hline $10 \mathrm{a}$ & None & Removal of & Thiop. (100) & $\mathrm{N}_{2} \mathrm{O} / \mathrm{Hal}$ & Mask & Spontaneous & 60 & \\
\hline $10 \mathrm{~b}$ & None & $\begin{array}{l}\text { pacemaker } \\
\text { Insertion of }\end{array}$ & Thiop. (100) & $\mathrm{N}_{2} \mathrm{O} / \mathrm{Hal}$ & Mask & Spontaneous & 60 & \\
\hline 11 & $\begin{array}{l}\text { Papa. (10), } \\
\text { Atrop. (0 6) }\end{array}$ & $\begin{array}{l}\text { pacemaker } \\
\text { Abdominoperineal } \\
\text { resection of }\end{array}$ & Thiop. (250) & $\begin{array}{l}\mathrm{N}_{2} \mathrm{O} / \mathrm{Hal}, \\
\text { Panc (6 mg) }\end{array}$ & E.T. tube & Artificial & 135 & \\
\hline 12 & None & $\begin{array}{l}\text { rectum } \\
\text { Suture of bleeding } \\
\text { ulcer and } \\
\text { vagotomy }\end{array}$ & Thiop. (250) & $\mathrm{N}_{2} \mathrm{O}$, Panc $(6 \mathrm{mg})$ & E.T. tube & Artificial & 120 & \\
\hline
\end{tabular}

Morph. = Morphine. Atrop. $=$ Atropine. Drop. $=$ Droperidol. Hydc. = Hydrocortisone. Papa. = Papaveretum. Hyosc. $=$ Hyoscine. Thio. $=$ Thiopentone. Hal. = Halothane. Panc. $=$ Pancuronium. E.T. = Endotracheal.

regional analgesia was instituted for control of postoperative pain in accord with current practice at this hospital (table I).

Operations.-The operations were predominantly abdominal and urogenital (table I). The series included no thoractomies or neurosurgical procedures but there was one operation for detachment of the retina.

\section{Results}

Preoperative Assessment.-All patients were dyspnoeic on exertion. One patient (case 1) gave a history of late onset asthma and two (cases 7 and 11) had unremitting dyspnoea without cough or sputum. The remaining nine patients had a history of chronic cough and expectoration. The FEV, ranged from 0.45-1.04 litres (body temperature and pressure, saturated with water) with a mean value of 0.78 , or $40 \%$ of predicted (table II). The mean $\mathrm{FEV}_{1}: \mathrm{VC}$ ratio was $43 \%$. Arterial carbon dioxide pressure $\left(\mathrm{PaCO}_{2}\right)$ was $6.0 \mathrm{kPa}(45 \mathrm{~mm} \mathrm{Hg})$ or above in four patients, though two of these had $\mathrm{FEV}_{1}$ values above 0.85 litres. $\mathrm{PaO}_{2}$ was below the normal range for patients' ages in all four patients with raised $\mathrm{PaCO}_{2}$ and in another three patients with normal or reduced $\mathrm{PaCO}_{.}$.

Anaesthesia.-No difficulties arose in the course of any anaesthetic. On the four occasions when patients breathed spontaneously they seemed to maintain satisfactory levels of ventilation as judged by

T ABLE II-Pulmonary Function Test Results. Oxygen Pressure Values that Fell below 2 S.D. of Predicted are Shown in Italic

\begin{tabular}{|c|c|c|c|c|c|c|c|}
\hline \multirow{2}{*}{$\begin{array}{l}\text { Case } \\
\text { No. }\end{array}$} & \multirow{2}{*}{$\begin{array}{c}\text { Age } \\
\text { and Sex }\end{array}$} & \multirow{2}{*}{$\begin{array}{c}\text { VC } \\
\text { (Litres) }\end{array}$} & \multirow{2}{*}{$\begin{array}{l}F E V_{1} \text { in Litres } \\
\text { (" } " \text { of Predicted) }\end{array}$} & \multirow{2}{*}{$\begin{array}{l}F E V_{1} \text { as } \\
\text { ", of VC }\end{array}$} & \multicolumn{3}{|c|}{ Blood Gases } \\
\hline & & & & & $\begin{array}{l}\mathrm{PaO}_{2} \\
(\mathrm{kPa})\end{array}$ & $\begin{array}{l}\mathrm{PaCO}_{2} \\
(\mathrm{kPa})\end{array}$ & $\mathrm{PH}$ \\
\hline $\begin{array}{r}1 \\
2 \\
3 \\
4 \\
5 \\
6 \\
7 \\
8 \\
9 \\
10 \\
11 \\
12\end{array}$ & $\begin{array}{l}56 \mathrm{M} . \\
57 \mathrm{M} . \\
76 \mathrm{M} . \\
77 \mathrm{M} . \\
70 \mathrm{M} . \\
69 \mathrm{M} . \\
73 \mathrm{~F} . \\
69 \mathrm{M} . \\
64 \mathrm{M} . \\
65 \mathrm{~F} . \\
88 \mathrm{~F} \\
70 \mathrm{M} .\end{array}$ & $\begin{array}{l}3.19 \\
1.75 \\
2.03 \\
2.30 \\
2.09 \\
1.85 \\
1.21 \\
2.10 \\
1.74 \\
1.32 \\
1.30 \\
1.43\end{array}$ & $\begin{array}{l}0.88(37) \\
0.82(30) \\
1.04(45) \\
0.86(41) \\
1.00(34) \\
0.88(34) \\
0.77(49) \\
0.80(27) \\
0.54(48) \\
0.45(24) \\
0.76(77) \\
0.50(35)\end{array}$ & $\begin{array}{l}28 \\
47 \\
51 \\
37 \\
48 \\
48 \\
64 \\
38 \\
31 \\
34 \\
59 \\
35\end{array}$ & $\begin{array}{r}10 \cdot 7 \\
10 \cdot 6 \\
\\
10.5 \\
6.4 \\
8 \cdot 8 \\
7 \cdot 8 \\
7 \cdot 2 \\
8 \cdot 5 \\
7.6 \\
5.9\end{array}$ & $\begin{array}{l}5 \cdot 6 \\
5 \cdot 1 \\
\\
5 \cdot 6 \\
6 \cdot 8 \\
6 \cdot 0 \\
4 \cdot 4 \\
5 \cdot 0 \\
6 \cdot 6 \\
5 \cdot 8 \\
7 \cdot 6\end{array}$ & $\begin{array}{l}7 \cdot 380 \\
7 \cdot 371 \\
7 \cdot 347 \\
7 \cdot 368 \\
7 \cdot 380 \\
7 \cdot 428 \\
7 \cdot 470 \\
7 \cdot 310 \\
7 \cdot 390 \\
7 \cdot 320\end{array}$ \\
\hline
\end{tabular}

Conversion: SI to Traditional Units-Blood gases: $1 \mathrm{kPa} \approx 7.5 \mathrm{~mm} \mathrm{Hg}$. observation of the reservoir bag and did not become cyanosed when breathing $35^{\circ}$, oxygen. The other patients were ventilated artificially without difficulty and air trapping was not clinically apparent.

\section{POSTOPERATIVE COURSE}

Table III summarizes the postoperative course and blood gas results. The time spent in the recovery room or intensive therapy unit was a measure of the opinion of the anaesthetist on the patient's recovery from the operation and anaesthetic. In nine cases the patient returned to the ward within four hours, after a stay which was within normal limits for the type of surgery undertaken. None of these patients gave any indication of difficulties referable to the respiratory system though two patients (cases 6 and 9) had a $\mathrm{PaCO}_{2}$ of 6.0 and $6.6 \mathrm{kPa}(45.0$ and $49.2 \mathrm{~mm} \mathrm{Hg}$ ) respectively, and two (cases 9 and 10) had $\mathrm{FEV}_{1}$ values of 0.54 litres and 0.45 litres respectively before operation. Early postoperative blood gas values in case 9 indicated a slight increase in $\mathrm{PaCO}_{2}$ from 6.6 to $7 \cdot 2 \mathrm{kPa}(49 \cdot 2$ to $54 \mathrm{~mm} \mathrm{Hg})$. Postoperative blood gases showed only usual changes in cases 2 and 7.

Three patients (cases 7, 10, and 11) were admitted to the intensive therapy unit overnight for observation. All three recovered normally from anaesthesia and received no ventilatory support.

Postoperative difficulties were encountered in three patients. One (case 8) had arterial hypoxaemia $\mathrm{PaO}_{2} 7.2 \mathrm{kPa}(53.9 \mathrm{~mm} \mathrm{Hg})$ before operation, which was accentuated after the operation. Two hours after operation his $\mathrm{PaO}_{2}$ was $12 \mathrm{kPa}(90 \mathrm{~mm} \mathrm{Hg}$ ) while breathing $50 \%$ oxygen and he was gradually weaned from oxygen-enriched gas mixtures over the next five days, by which time he had a $\mathrm{PaO}_{2}$ of $5.9 \mathrm{kPa}$ $\left(44 \mathrm{~mm} \mathrm{Hg}\right.$ ) when breathing air. $\mathrm{PaCO}_{2}$ rose to $6.7 \mathrm{kPa}(50 \mathrm{~mm} \mathrm{Hg})$ during the first few hours after operation but was within the normal range the next day. Ventilatory support was not required and he received no respiratory treatment other than oxygen and physiotherapy. There were no significant changes in four postoperative chest $x$-ray films other than slight opacity at the left costophrenic angle. The intercostal block provided 12 hours of analgesia and no postoperative opiates were required. He left hospital 13 days after his cholecystectomy.

One patient (case 5) who had preoperative hypercapnia was unable to breath satisfactorily after operation and was ventilated artificially for 24 hours. On return of spontaneous respiration $\mathrm{PaCO}_{2}$ ranged from 7.5 to $8.4 \mathrm{kPa}(56-63 \mathrm{~mm} \mathrm{Hg}$ ) during the first four hours, but thereafter returned to its preoperative level. Oxygenation of arterial blood was impaired for 48 hours $\left(\mathrm{PaO}_{2} 5.7 \mathrm{kPa}, 43 \mathrm{~mm} \mathrm{Hg}\right)$ while breathing air 
TABLE III-Postoperative Course in 12 Patients. Blood Gases were Estimated on Day of Operation, usuaily Two to Four Hours after Operation

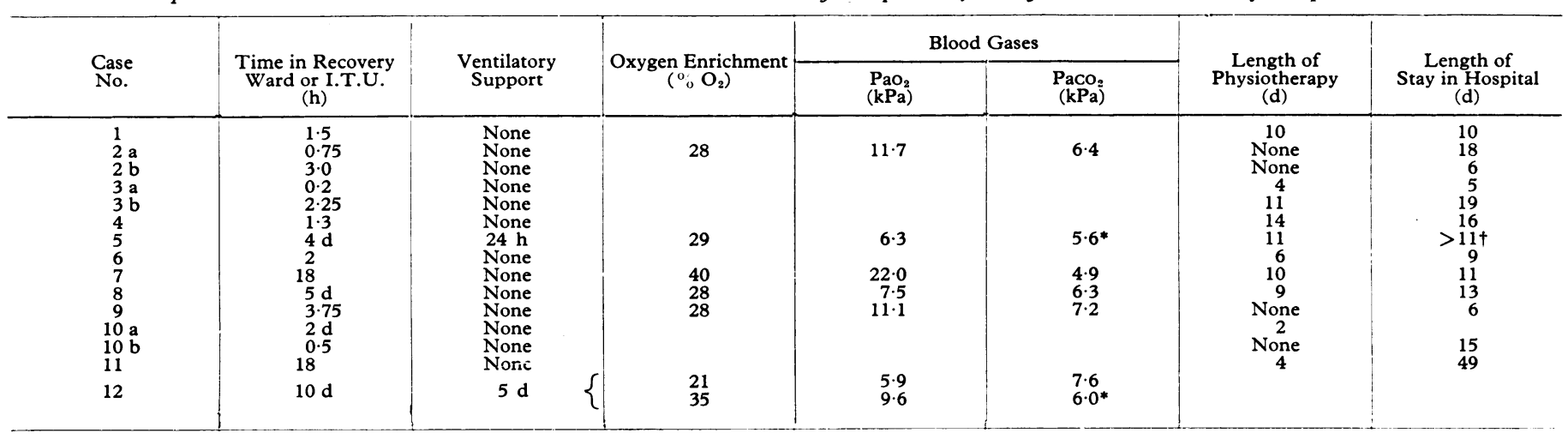

* On intermittent positive pressure ventilation. †Transferred to another hospital.

24 hours after operation), and oxygen enrichment (24-33\%) was used for 48 hours. Physiotherapy was continued for 11 days, after which he was transferred to an ophthalmic unit. Postoperative chest $x$-ray examination showed a band shadow at the left base which could have been due to a pulmonary infarct, but there was no other evidence for this and the shadow resolved.

The third patient requiring postoperative respiratory treatment (case 12) was admitted as an emergency with upper gastrointestinal bleeding. Postoperative artificial ventilation was clearly indicated on clinical grounds and continued uneventfully for five days. On return to spontaneous breathing he maintained $\mathrm{PaCO}_{2}$ in the range 7.2-7.9 $\mathrm{kPa}(54-59 \mathrm{~mm} \mathrm{Hg})$ and required oxygen-enrichment of inspired gas $\left(\mathrm{PaO}_{2} 5.3 \mathrm{kPa}(40 \mathrm{~mm} \mathrm{Hg})\right.$ breathing air). He left the intensive therapy unit after 10 days with a $\mathrm{PaCO}_{2}$ of $8.1 \mathrm{kPa}(61.0 \mathrm{~mm} \mathrm{Hg})$ and a $\mathrm{PaO}_{2}$ of $7.7 \mathrm{kPa}(57.7 \mathrm{~mm} \mathrm{Hg})$ breathing air. Physiotherapy was continued for 21 days.

\section{Discussion}

From this survey we may distinguish three groups of patients who present for surgery with chronic obstructive airway disease. Firstly, those patients with low $\mathrm{FEV}_{1}$ but normal $\mathrm{PaCO}_{2}$ and without overt arterial hypoxaemia $\left(\mathrm{PaO}_{2}>7.3 \mathrm{kPa}(55 \mathrm{~mm} \mathrm{Hg})\right)$. This group included cases $1,2,4,7,10$, and probably 3 and 11 , in whom arterial blood gases were not measured because this did not seem necessary. No patient in this group gave the least cause for anxiety even though preoperative values for $\mathrm{FEV}_{1}$ were grossly reduced. Routine anaesthetic techniques and normal postoperative attention gave entirely satisfactory results.

The second group consists of patients with low $\mathrm{FEV}_{1}$ and low $\mathrm{PaO}_{2}(<7.3 \mathrm{kPa})$ but normal $\mathrm{PaCO}_{2}$. Only one of our patients (case 8) fell into this group. The only special treatment was the prolonged use of oxygen during the postoperative period, when the inspired oxygen concentration was titrated against his $\mathrm{PaO}_{2}$ to give a safe value. He was treated in the intensive therapy unit more for convenience than for medical necessity.

The third group consists of patients with hypercapnia $\left(\mathrm{PaCO}_{2}>5.9 \mathrm{kPa}(>44 \mathrm{~mm} \mathrm{Hg})\right)$, greatly reduced $\mathrm{FEV}_{1}$, and $\mathrm{PaO}_{2}$ more than 2 S.D. below the normal range. This group included four of our patients (cases 5, 6, 9, and 12), overt hypoxaemia $\left(\mathrm{PaO}_{2}<7.3 \mathrm{kPa}\right)$ was present in cases 5 and 12 . Two patients (cases 6 and 9) had only moderate hypercapnia $\left(\mathrm{PaCO}_{2} 6 \cdot 0-6 \cdot 6 \mathrm{kPa}(45 \cdot 0-49 \cdot 2 \mathrm{~mm} \mathrm{Hg})\right)$ and made uneventful recoveries from prostatectomy with no special respiratory treatment. The two patients with hypoxaemia and $\mathrm{PaCO}_{2}$ in the range $6 \cdot 8-7 \cdot 6 \mathrm{kPa}(50 \cdot 9-57 \cdot 3 \mathrm{~mm} \mathrm{Hg}$ ) (cases 5 and 12), however, needed full ventilatory support in the postoperative period.

We attach considerable importance to the fact that none of our patients had appreciable secretions at the time of operation. This was due partly to preoperative physiotherapy and antibiotics and partly to the changing pattern of chronic bronchitis which over the past 10 years has shown far less of the copious purulent secretions that presented such difficulties to the anaesthetist in former times. Howard ${ }^{6}$ has attributed the less rapid progression of the disease and the diminished role of infection to the clean air policy and, certainly, we are now seeing a different type of patient from those seen and anaesthetized immediately after the war.

There are few studies of the predictive value of pulmonary function tests in patients with obstructive airways disease undergoing anaesthesia and surgery. Stein et al. ${ }^{2}$ reported a series of 63 randomly selected patients, 30 of whom were classified as abnormal on lung function testing. Respiratory complications were almost exclusively confined to this group. The best predictive test was found to be maximum expiratory flow rate, which correlates well with $\mathrm{FEV}_{1}$. These authors also found that a raised $\mathrm{PaCO}_{2}$ was associated with serious respiratory complications in every case. Appleberg et al., ${ }^{1}$ in a similar study, found that simple lung function tests increased the ability to predict those patients likely to have postoperative respiratory problems. Lockwood $^{8}$ followed up 81 patients after cardiothoracic operations and found that both respiratory and cardiac complications were more common among patients with abnormal function test results. His results suggested that measurements of lung volumes, especially residual volume, might provide a sensitive predictive test of postoperative respiratory complications. Anderson and $\mathrm{Ghia}^{\circ}$ also found a good correlation between tests of airways resistance and postoperative course in cardiothoracic patients, including open heart cases.

In none of these studies are there any recommendations on the lower limit of values for acceptance for surgery. We do not believe that a reduced $\mathrm{FEV}_{1}$ without hypercapnia or hypoxia is a barrier to routine surgery. Values below 1 litre or $50 \%$ of predicted clearly demand that the patient should be carefully monitored after operation but are compatible with normal recovery from surgery. Admission to the intensive therapy unit may be advisable overnight after surgery.

In patients with low $\mathrm{FEV}_{1}$ and arterial hypoxaemia but no hypercapnia there should also be no barrier to routine surgery but $\mathrm{PaO}_{2}$ must be carefully monitored and oxygen treatment provided to correct any tendency to deterioration of $\mathrm{PaO}_{2}$ after the operation. This may be more convenient in an intensive therapy unit if that is where blood-gas measurement is carried out. The most important aspect of preoperative respiratory assessment is a raised $\mathrm{PaCO}_{2}$. A slight increase may offer no appreciable difficulty but an increase above $6.7 \mathrm{kPa}(50 \mathrm{~mm} \mathrm{Hg})$ often indicates the need for postoperative artificial ventilation requiring prolonged endotracheal intubation or, rarely, tracheostomy.

Hence, the most important preoperative test is measurement of the arterial blood gases, because this shows the most significant abnormalities. Measurement of $\mathrm{FEV}_{1}$ (or peak expiratory flow) is convenient and is likely to show an abnormality in any patient with chronic obstructive airway disease but it fails to distinguish those patients who are likely to require ventilatory support after operation. It therefore has a role as a preliminary screen but should be supplemented by measurement of arterial blood gases in patients with low values. We regard 1 litre or $50 \%$ of predicted 
as the lowest values for $\mathrm{FEV}_{1}$ that should be accepted for surgery without measurement of arterial blood gases.

Patients thus selected will benefit from preoperative physiotherapy and antibiotics, ${ }^{10}$ but we do not advocate any one anaesthetic technique as being superior to others for these patients. The important points are preoperative assessment and an awareness of the relevant pathophysiology. Spontaneous respiration seems acceptable for minor procedures not requiring relaxation; controlled ventilation is probably indicated in more prolonged anaesthesia. Regional analgesia for postoperative pain avoids the need for using morphine in patients who may have reduced respiratory sensitivity to carbon dioxide.

We thank Miss Anne Barrett who carried out most of the lung function tests and blood gas estimations and our surgical and anaesthetic colleagues who were involved in the care of these patients.

\section{References}

1 Diament, M. L., and Palmer, K. N. V., Lancet, 1967, 1, 1251.

2 Stein, M., et al., fournal of the American Medical Association, 1962, 181, 765 .

${ }^{3}$ Thornton, J. A., Problem of Anaesthesia and Surgery in Relation to Chronic Respiratory Disease, M.D. Thesis, University of London, 1969.

${ }^{4}$ Cotes, J. E., Lung Function, Assessment and Application in Medicine. Oxford, Blackwell, 1965.

${ }^{5}$ Raine, J. M., and Bishop, J. M., Fournal of Applied Physiology, 1963, 18, 284.

- Howard, P., British Medical fournal, 1972, 2, 89.

${ }^{7}$ Appleberg, M., Gordon, L., and Fatti, L. P., British fournal of Surgery, $1974,61,57$.

${ }^{8}$ Lockwood, P., Respiration, 1973, 30, 105.

${ }^{9}$ Andersen, N. B., and Ghia, J., Fournal of Thoracic and Cardiovascular Surgery, 1970, 59, 474.

${ }^{10}$ Stein, M., and Cassara, E. L., fournal of the American Medical Association, 1970, 211, 787.

\title{
Assessment of Regional Ventilation by Continuous Inhalation of Radioactive Krypton-81m
}

\author{
F. FAZIO, T. JONES
}

British Medical fournal, 1975, 3, 673-676

\section{Summary}

A simple technique is described for producing highquality functional images of regional ventilation during physiological tidal breathing of the inert gas ${ }^{81 \mathrm{~m}} \mathbf{K r}$. These images are quickly obtained on a gamma-camera without the need of computerized systems for data acquisition and display and are directly comparable with those of perfusion obtained with ${ }^{9} \mathrm{~mm}$ Tc-labelled macroaggregates. The short time required for the procedure, its simplicity, and the extremely low absorbed-radiation dose enable serial images of ventilation to be obtained in multiple views.

\section{Introduction}

There is a need for a technique to obtain functional images of ventilation that are comparable to the routinely obtained macroaggregate perfusion scan.' Previous methods have involved wash-in, wash-out, or a single breath of radioactive gases or aerosols of labelled particles. Because these methods tend to be either complex or inaccurate and unphysiological they have had limited clinical application.

We present here a new simple technique to obtain functional images of the regional ventilation using a gamma-camera during tidal breathing of the inert gas ${ }^{81 \mathrm{~m}} \mathrm{Kr}$. This method overcomes many of the limitations of previous techniques and when used in conjunction with perfusion data provides unique information on regional mismatching of ventilation and perfusion.

Department of Medicine, Hammersmith Hospital, London W12 0HS F. FAZIO, M.D., Wellcome Trust Research Fellow

M.R.C. Cyclotron Unit and Department of Diagnostic Radiology, Hammersmith Hospital, London, W12 0HS

T. JONES, M.sc., B.Sc., Medical Physicist

\section{Theory}

Continuous inhalation of an inert gas results in equilibration of the gas in the lungs. If a radioactive gas with a long half life is used the count rate at equilibrium, as measured externally over the chest, will be proportional to lung volume rather than to ventilation. Regional ventilation can be assessed only from the rate of equilibration (washin) or elimination (wash-out) of the gas.

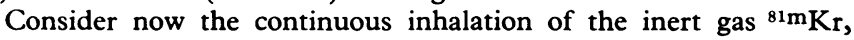
which has a radioactive half life of 13 seconds. The rapid radioactive decay of this gas relative to the ventilation turnover rate per unit volume will result in an alveolar concentration at equilibrium much less than that in the inspired air. Hence the contribution of the ${ }^{8} 1 \mathrm{mKr}$ wash-out to this dynamic process is small. Equilibration of the isotope in the lung therefore depends on the balance between arrival of ${ }^{81} \mathrm{mKr}$ and radioactive decay. ${ }^{81 \mathrm{~m} K r}$ lung counts are theoretically proportional to

$$
\frac{\dot{\mathrm{V}}}{\dot{\mathrm{V}} / \mathrm{vol}+\lambda}
$$

where $\dot{\mathrm{V}}$ is total ventilation, $\dot{\mathrm{V}} /$ vol the ventilation per unit of lung volume, and $\lambda$ the radioactive decay constant of $81 \mathrm{mKr}$, which is $3 \cdot 2 / \mathrm{min}$. The denominator is dominated by the high value for $\lambda$, hence the lung signal is more dependent on ventilation $(\dot{V})$ than on ventilatory wash-out $(\dot{\mathrm{V}} / \mathrm{vol})$. This results in an almost linear relation between radioactivity and regional ventilation for both normal (about $1.01 \mathrm{~min}^{-1} \mathrm{l}^{-1}$ ) and reduced ventilation rates in adults (fig. 1).

Therefore, the equilibrium images recorded with the gammacamera during the continuous inhalation of $81 \mathrm{~m} \mathrm{Kr}$ reflect the regional arrival of the gas-that is, ventilation. In other words, continuous tidal breathing of ${ }^{81 \mathrm{mKr}}$ effectively produces the same information as the sum of a series of separate tidal breaths of a radioactive gas with a long half life.

\section{Methods}

The ${ }^{81 \mathrm{~m} K r}$, which emits $190 \mathrm{keV}$ gamma-rays, can be produced continuously by passing air through a cation exchange column to which its parent isotope ${ }^{81} \mathrm{Rb}$ is bound. ${ }^{81} \mathrm{Rb}$ has a half life of four and a half hours and is produced for us on the M.R.C. cyclotron. ${ }^{2}$ The half life of the parent enables ${ }^{81 \mathrm{~m}} \mathrm{Kr}$ to be continuously available all day for ventilation measurements after a morning production of ${ }^{81} \mathrm{Rb}$.

If both ventilation and perfusion scans are required $1 \mathrm{mCi}$ of $99 \mathrm{mTc}$-labelled macroaggregates or microspheres (99m Tc-HAM) is first injected intravenously with the patient in the seated position. The patient is then positioned in front of the gamma-camera (Toshiba 